\title{
ANALYSIS OF CONTROL SYSTEMS FOR VEHICLE HYBRID POWERTRAINS
}

\author{
Siarhei Kliauzovich \\ Dept of Automotive Engineering, Belarusian National Technical University, pr. Nezavisimosti 65, \\ 220013 Minsk, Belarus. Phone: +375 29 7527728,E-mail: klevzik@mail.ru
}

Received 4 January 2007, accepted 1 February 2007

\begin{abstract}
Ecological and socioeconomic factors determine high interest in the development of pollution-free vehicles. At present use of electro-vehicles is suppressed by a number of technological factors. Vehicles with alternative powertrains are transitional stage between development of pollution-free vehicles and vehicles with conventional internal combustion engine. According to these aspects the investigation on conventional hybrid drives and their control systems is carried out in the article. The equations that allow evaluating effectiveness of regenerative braking for different variants of hybrid drive are given. The AMESim software is used as the modeling environment, in which models of hybrid vehicles are developed and the results of virtual simulation are analyzed. Also a number of recommendations for increasing of regenerative braking effectiveness are given.
\end{abstract}

Keywords: parallel hybrid drive, series hybrid drive, regenerative brake system, AMESim, simulation, driving cycle.

\section{Application of hybrid powertrains in modern vehicles}

Decreasing of exhaust toxicity was the main increment in the development of pollution-free vehicles with alternative powertrains. Complete refusal of internal combustion engines was suppressed in the absence of power-consuming, lightweight and low-cost batteries and also with the necessity to develop electrical stations for power supply of such vehicles on the analogy of filling stations.

At present the increased interest in the development of vehicles with hybrid powertrains is to be observed. This tendency is determined by a number of factors:

- the necessity to improve fuel efficiency;

- toughening of exhaust toxicity standards;

- continual growth of prices for fuel and energy resources;

- finitness of mineral wealth.

Hybrid automobiles in classical representation are vehicles with two propulsion systems: internal combustion engine and electric motor. Basically, there are two main ways of realizing hybrid drive: parallel (Fig 1) and series (Fig 2) [1].

In parallel drive wheels are driven by both internal combustion engine and electric motor. However, usual transmission is required in that case and the engine has to perform in uneconomical acceleration modes. In series drive the engine rotates only generator, operating thus in stationary mode and wheels have a mechanical connection only with electric motor.

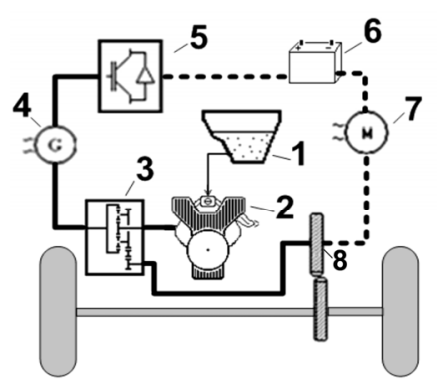

Fig 1. Parallel hybrid vehicle:

1 - fuel tank; 2 - internal combustion engine; 3 - mechanism for splitting and transfer of power; 4 - generator; 5 - voltage transducer; 6 - battery; 7 - electric motor; 8 - reduction gear; power circuits: - - - electrical, mechanical

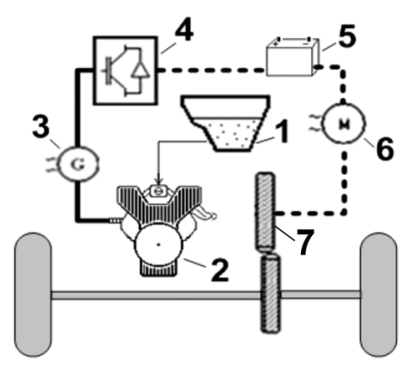

Fig 2. Series hybrid vehicle:

1 - fuel tank; 2 - internal combustion engine; 3 - generator; 4 - voltage transducer; 5 - battery; 6 - electric motor; 7 - reduction gear; power circuits: - - electrical, mechanical 
Let us analyze the principle of operation of hybrid vehicle with parallel drive more in detail.

During starts or moves at low velocities $(\sim 15 \ldots 20 \mathrm{~km} / \mathrm{h})$ only electric motor 4 and storage battery 7 are used in parallel hybrid vehicle (Fig 3).

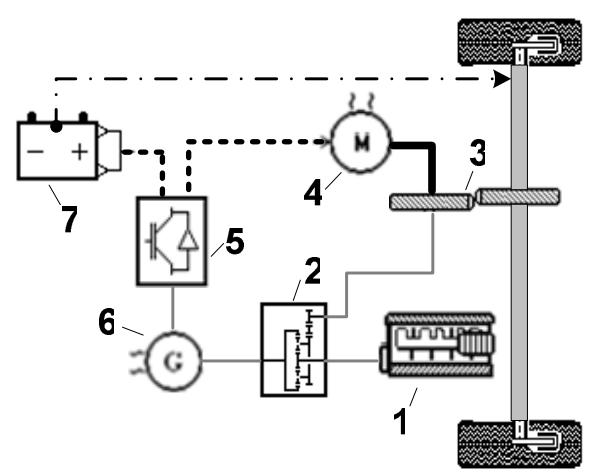

Fig 3. Start and movement at low speed to Figs 3-6: 1 - internal combustion engine; 2 - planetary gear; 3 - reduction gear; 4 - electric motor; 5 - commutator; 6 - generator;

7 - battery; on Figs: solid heavy lines indicate the way of torque, dash heavy lines indicate electric power way, dashdot lines-total power

At the low and medium loads engine 1 starts, moreover its torque splits - about $70 \%$ is directed directly to the wheels, while $30 \%$ is separated from planetary gear set 2 and through generator 6 and electric motor 4 also goes to the wheels (Fig 4).

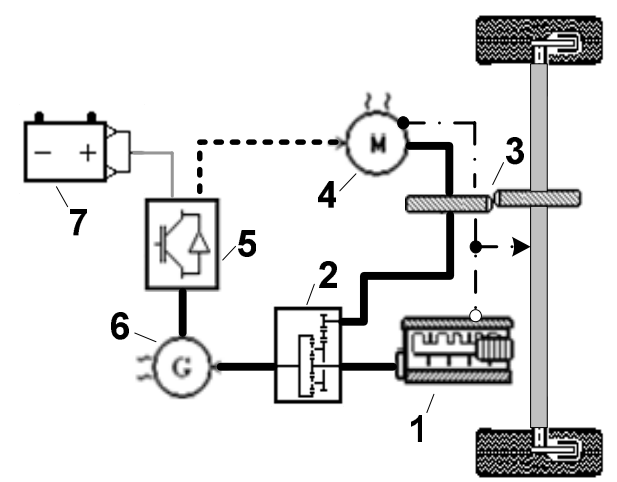

Fig 4. Low and medium load

In intensive acceleration mode the electric motor 4 in addition to the part of energy from engine 1 receives complementary energy from the storage batteries 7 (Fig 5).

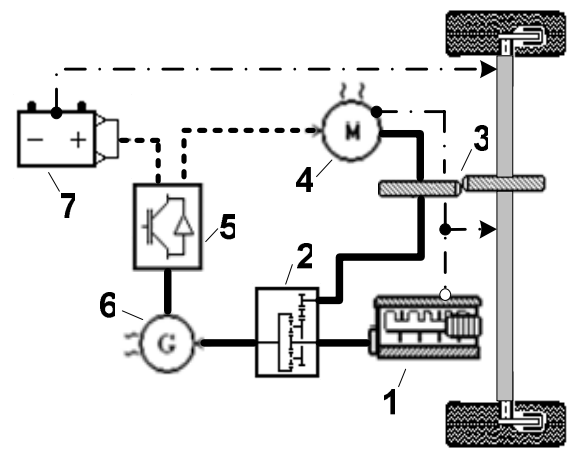

Fig 5. Full load
During braking, engine 1 stops while electric motor 4 operates in recuperation mode, as generator, charging the battery (Fig 6).

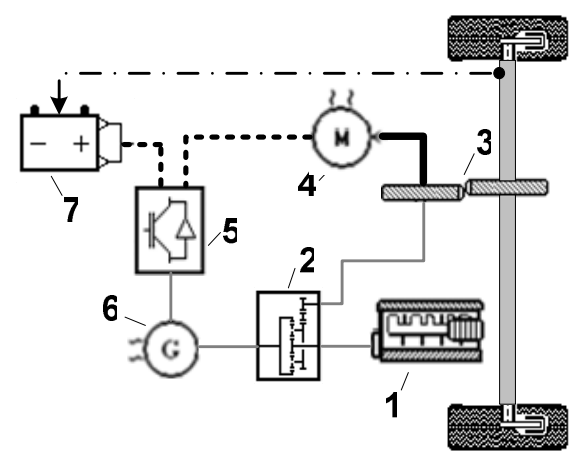

Fig 6. Regenerative braking

Modes and power flows operating are entrusted to control system. Algorithm of control system functioning in conventional modes of load mentioned above is not basic. It just shows the general principle of work. Usually, producers appropriate a lot more sub-modes and, in accordance with them, organize detailed control algorithm for power flows.

As far as the configuration of hybrid vehicle with series drive differs from parallel hybrid vehicle fundamentally, then operating modes also differ. So, the next question is the operating principle of hybrid vehicle with series drive.

The main task of control system for hybrid vehicle with series drive is to provide engine performance with optimum ratio of torque and revolution, and at the same time to charge the battery and to drive the wheels with the help of electric motor.

In series hybrid vehicle the internal combustion engine is not connected mechanically with wheels. Engine rotates generator and the generator charges the battery. According to driving mode the traction motors receive the current either from batteries or directly from generator and batteries in addition if necessary.

When series hybrid vehicle starts or moves at low velocities only electric motor 3 and storage battery 6 are used (Fig 7). Engine starts when the level of battery charge decreases to certain value (about $20 \%$ ).

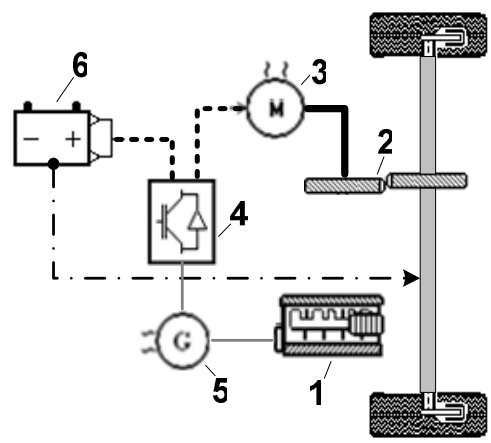

Fig 7. Start and movement at low speed to Figs 7-10: 1 - internal combustion engine; 2 - reduction gear;

3 - electric motor; 4 - commutator; 5 - generator; 6 - battery; on Figs: solid heavy lines indicate the way of torque, dash heavy lines indicate electric power way, dashdot lines-total power 
At the low and medium loads the internal combustion engine 1 starts, moreover it operates with optimum ratio of torque and revolution and by way of generator 5 and electric motor 3 drives the wheels. Besides, the engine charges the batteries 6 (Fig 8).

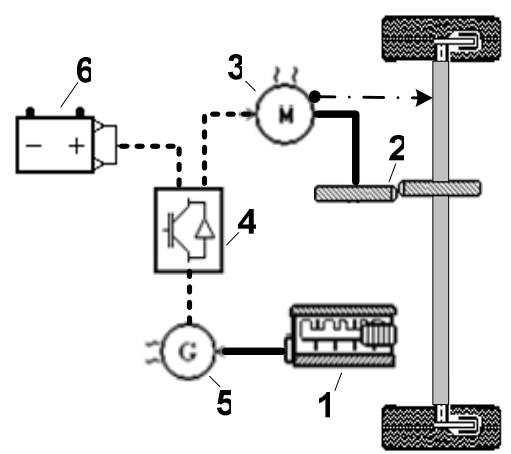

Fig 8. Low and medium load

During intensive acceleration mode the electric motor 3 in addition to the part of energy from engine 1 receives complementary energy from the storage batteries 6 (Fig 9).

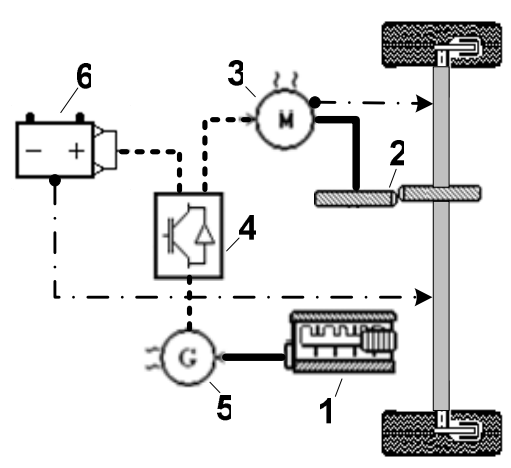

Fig 9. Full load

During braking, engine 1 stops while electric motor 3 operates in regeneration mode, as generator, charging the battery (Fig 10).

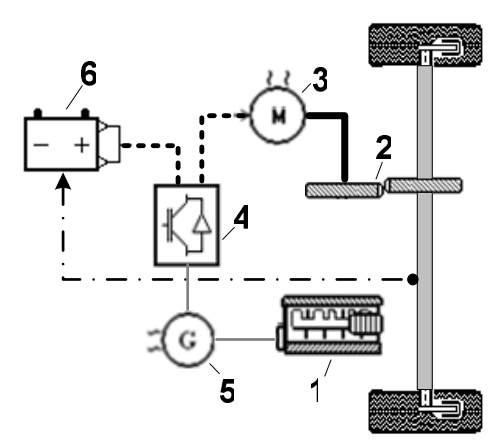

Fig 10. Regenerative braking

As the category of hybrid vehicles is the object of higher interest, then, proposed configurations are various. Today a lot of vehicle models with hybrid drive are in serial production: Toyota Prius, Honda Insight,
Honda Civic Hybrid, Dodge Ram Hybrid, Lexus RX 330 Hybrid, Ford Escape HEV and many others. Besides, a lot of hybrid vehicles and buses are planned for production in the near future [2].

High interest and the onrush of hybrid vehicle are conditioned by a number of hybrid drive advantages:

- decreasing of fuel consumption and of exhaust emissions;

- $\quad$ possibility of braking energy regeneration;

- $\quad$ possibility of using in hybrid vehicles the internal combustion engine with decreased volume preserving dynamic characteristics;

- possibility to refuse conventional transmission because of using hub motors;

- possibility of simple organization of all wheels drive using hub motors.

The disadvantages of hybrid drive are:

- decreasing of efficiency coefficient due to serial and multiple energy conversion;

- $\quad$ rise in the cost of vehicle;

- low percentage of recovered energy;

- complexity of recovered energy estimation;

- $\quad$ large unsprung mass when using hub motors.

According to different evaluations from 20 to $40 \%$ of mechanical tractive power is lost during braking. For example, it equals fuel consumption increase by 2-3 $1 / \mathrm{km}$ for midget cars [3]. These data show the urgency of braking energy regeneration use. Estimation of recovered energy is very important at the design stage since it helps to find out which scheme is more effective for this type of vehicle. Version of task decision at the design stage is under discussion further.

\section{Energy balance}

Within the bounds of the present research the question of qualitative evaluation of regenerative power during hybrid vehicle braking is of fundamental importance. Since the approach to estimation of total power of propulsion system in contrast to conventional vehicles with internal combustion engines depends on drive configuration and parameters of the system, that accumulates energy, initially the following conditions were used [4]:

- Vehicle power during braking on horizontal road $P_{b r}$ can be expressed by the following equation:

$P_{b r}=k_{m} \cdot m \cdot a \cdot V$,

where: $k_{m}$ - coefficient of rotational masses; $m-$ vehicle mass; $a$ - vehicle acceleration (deceleration); $V$ - vehicle velocity.

For definition of $k_{m}$ coefficient the chart in Fig 11 can be used.

- The power, that can be received during regenerative braking $P_{\text {regen }}$ :

$$
P_{\text {regen }}=k_{m} \cdot m \cdot a \cdot V \cdot \eta_{\text {regen }},
$$


where: $k_{m}$ - coefficient of rotational masses; $m-$ vehicle mass; $a$ - vehicle acceleration (deceleration); $V$ - vehicle velocity; $\eta_{\text {regen }}-$ efficiency of regenerative braking (can be defined as the rate of energy, received during braking up to decrease of vehicle kinetic energy).

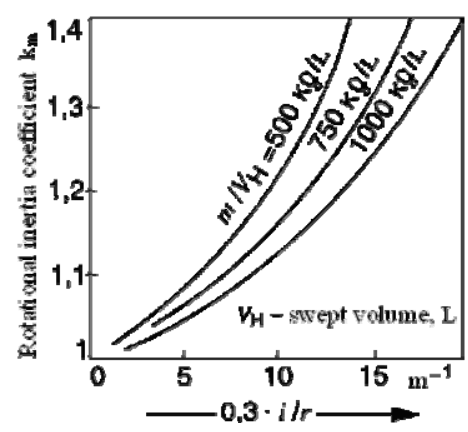

Fig 11. Definition of rotational inertia coefficient

- At the same time, regenerative braking power can be considered as electric power, that finally receives the storage element (in this case battery):

$P_{\text {regen }}=P_{\text {el }}=I_{\text {bat }} \cdot U_{\text {bat }}$,

where: $P_{e l}$ - electric power that receives battery; $I_{b a t}$ - battery current; $U_{b a t}$ - battery voltage.

- The effectiveness of regenerative braking can be estimated using these equations:

$$
\eta_{\text {regen }}=\frac{P_{\text {regen }}}{P_{b r}}=\frac{I_{b a t} \cdot U_{b a t}}{k_{m} \cdot m \cdot a \cdot V} \text {. }
$$

\section{Hybrid vehicle model}

For carrying out comparative tests two general models of hybrid drive were selected: series and parallel. AMESim software was used as the modeling environment.

AMESim means Advanced Modeling Environment for performing Simulations of engineering systems. The producer of this programming tool set is IMAGINE corporation [5].

The simulation models of hybrid vehicles realized with AMESim software are shown in Figs 12 and 13.

A passenger car with the following parameters served as the basis for models:

- $\quad$ vehicle mass $1200 \mathrm{~kg}$;

- $\quad$ swept volume of engine 2,0 1;

- $\quad$ tires size 185/65 R15;

- $\quad$ air penetration coefficient $\left(C_{x}\right) 0,36$.

At present one of the main problems of investigation on hybrid vehicles is that there are no standards and procedures for estimation of energy regenerated during braking.

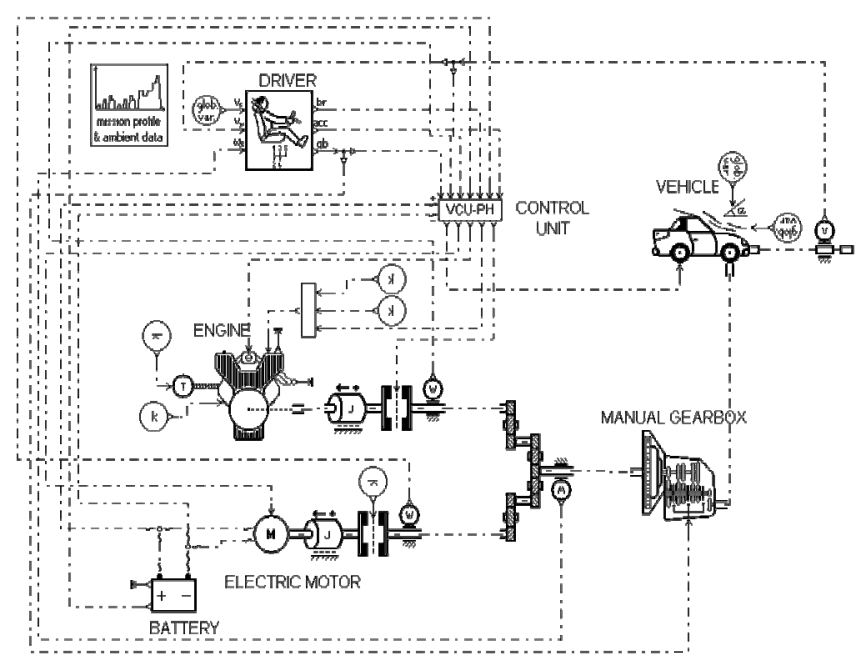

Fig 12. Simulation model of hybrid vehicle with parallel drive realized with AMESim software

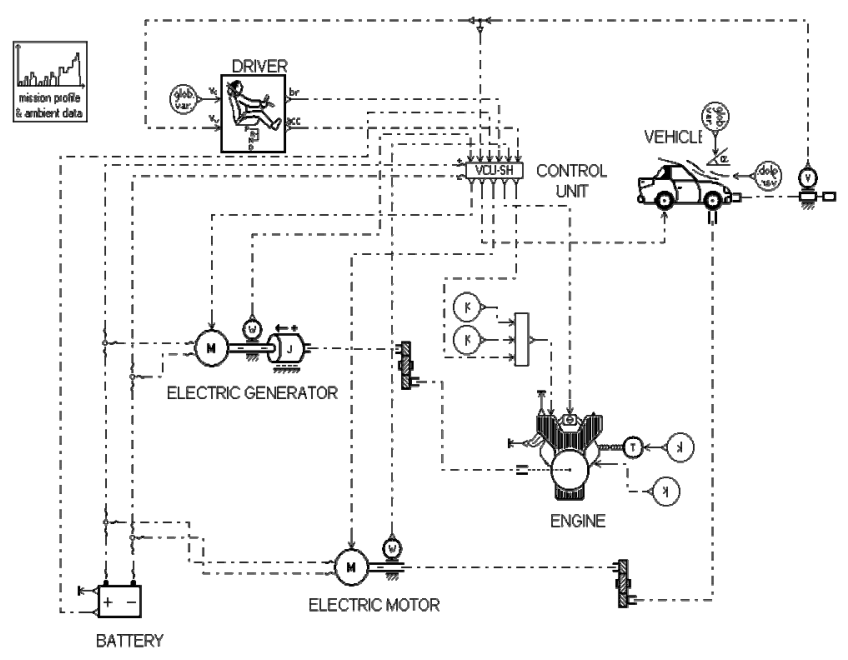

Fig 13. Simulation model of hybrid vehicle with series drive realized with AMESim software

Reasoning from considerations that for every vehicle type the most typical operating conditions are selected, then, for a passenger car such conditions involve the city cycle for which non-stationary motion is typical.

Non-stationary motion can be characterized by increased fuel consumption and correspondingly by higher atmospheric emission of harmful substances. In general the city cycle represents series of accelerations and brakings. From these positions the authors offer New European and Japanese 10-15 driving cycles for carrying out tests on energy recuperation. In Figs 14 and 15 charts of Japanese and new European driving cycles are presented [6].

In Table 1 some characteristics of the abovementioned driving cycles are shown [7]. 


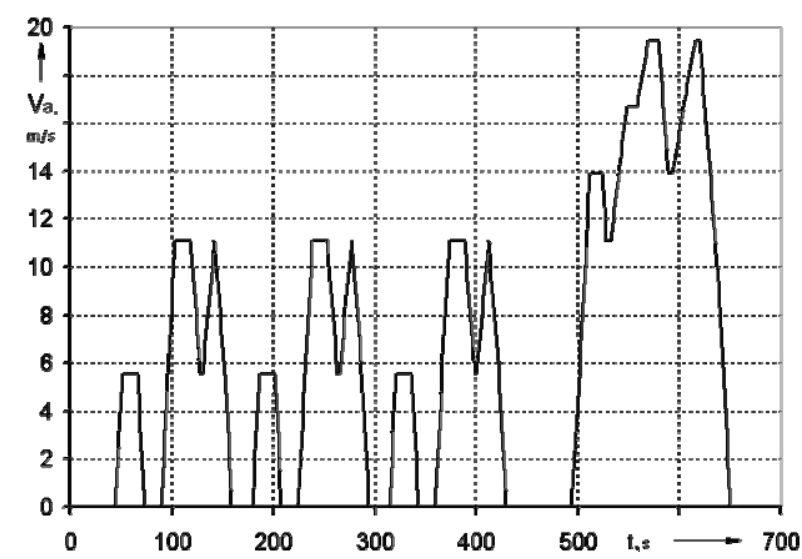

Fig 14. Japanese driving cycle (“10-15”)

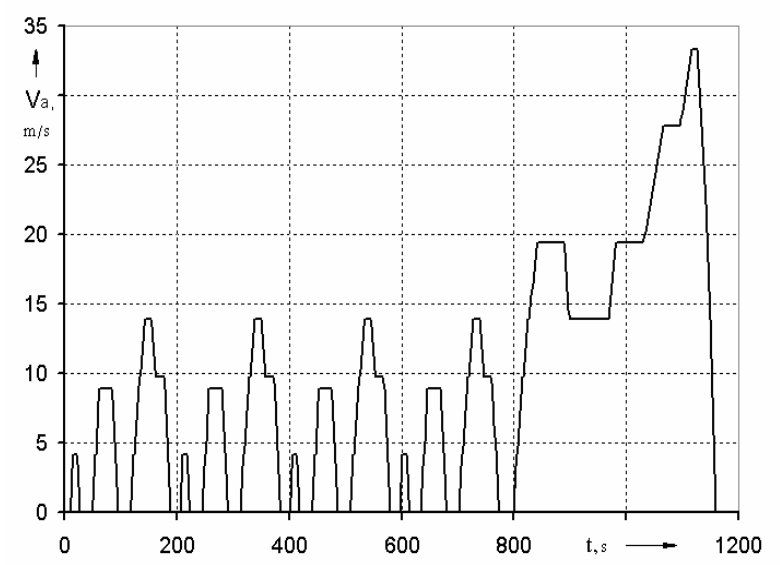

Fig 15. New European driving cycle (NEDC)

Table 1. Characteristics of Japanese and New European driving cycles

\begin{tabular}{|l|c|c|}
\cline { 2 - 3 } \multicolumn{1}{c|}{} & \multicolumn{2}{c|}{ Driving cycle } \\
\cline { 2 - 3 } \multicolumn{1}{c|}{} & Japanese & $\begin{array}{c}\text { New } \\
\text { European }\end{array}$ \\
\hline Duration, s & 660 & 1180 \\
\hline $\begin{array}{l}\text { Percent of braking or } \\
\text { stop time, \% }\end{array}$ & 52,3 & 24,9 \\
\hline Distance, $\mathrm{km}$ & 4,16 & 10,944 \\
\hline Average speed, $\mathrm{km} / \mathrm{h}$ & 23,68 & 33,44 \\
\hline Maximum speed, $\mathrm{km} / \mathrm{h}$ & 69,6 & 119,36 \\
\hline Peak acceleration, $\mathrm{m} / \mathrm{s}^{2}$ & 0,79 & 1,07 \\
\hline
\end{tabular}

\section{Simulation results and its analysis}

Figs 16-19 illustrate power characteristics received as a result of modelling.

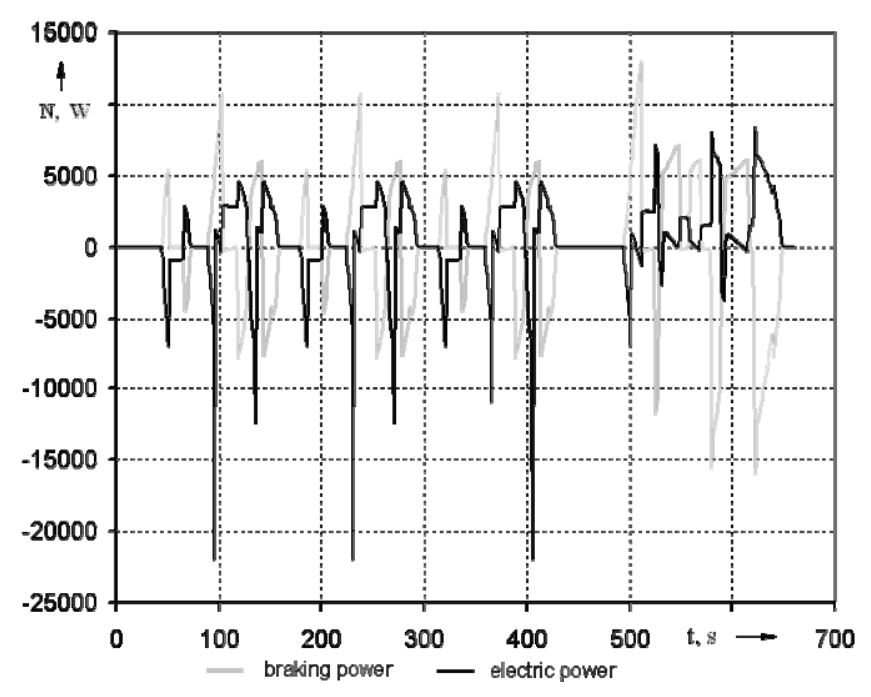

Fig 16. Power characteristics of series hybrid drive, Japanese driving cycle

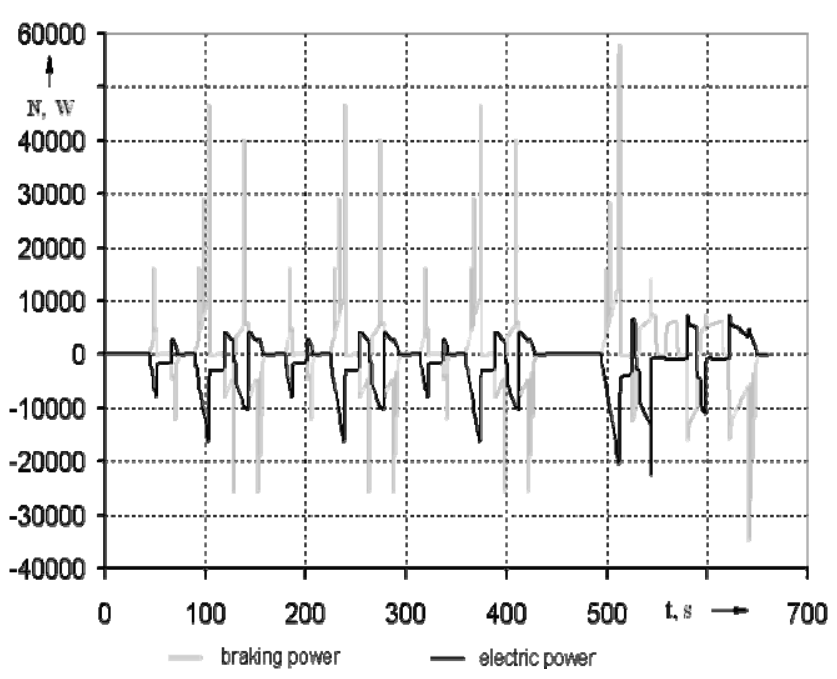

Fig 17. Power characteristics of parallel hybrid drive, Japanese driving cycle

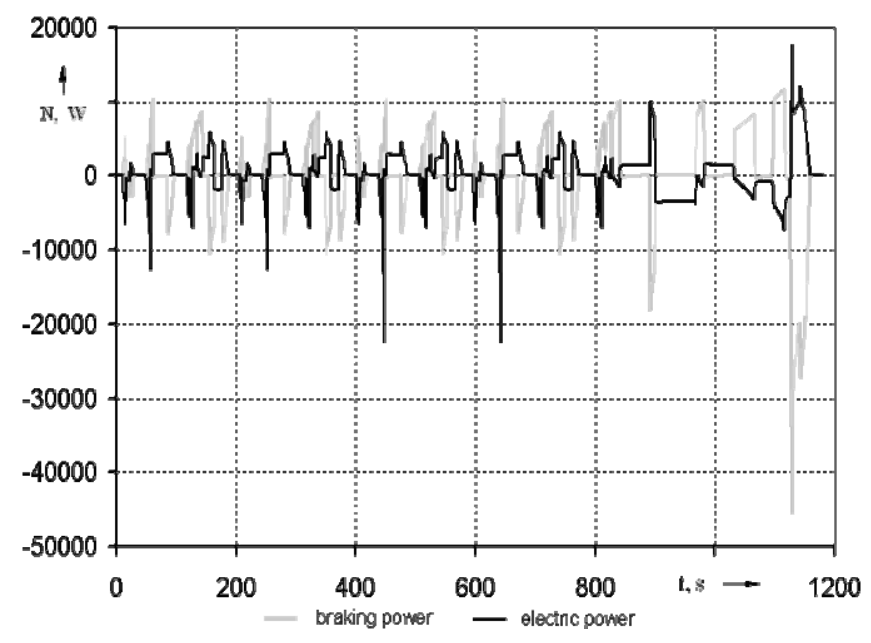

Fig 18. Power characteristics of series hybrid drive, New European driving cycle 


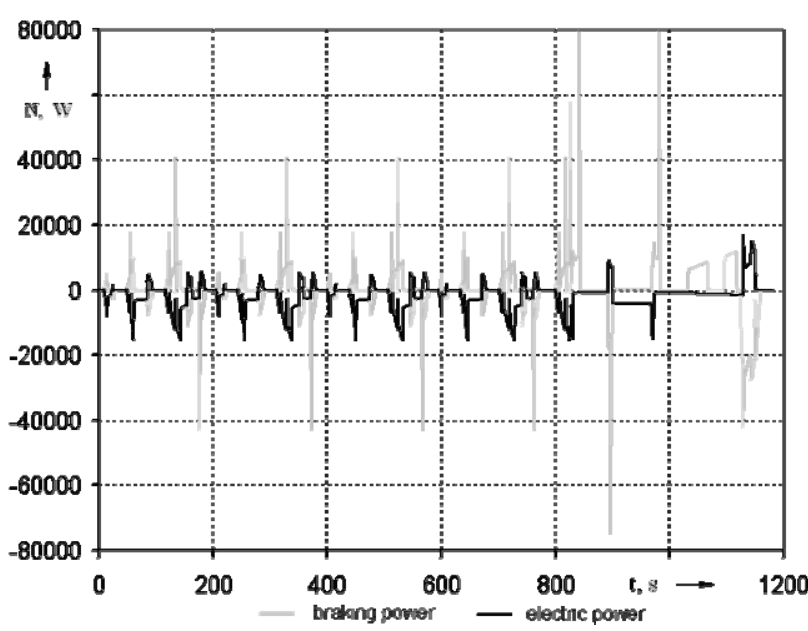

Fig 19. Power characteristics of parallel hybrid drive, New European driving cycle

The analysis of modelling results is presented in Table 2. As shown in Table 2 the percent of energy regenerated during braking varies depending on type of drive and driving cycle.

Table 2. Results of modeling

\begin{tabular}{|l|c|c|}
\cline { 2 - 3 } \multicolumn{1}{c|}{} & \multicolumn{2}{c|}{ Driving cycle } \\
\cline { 2 - 3 } \multicolumn{1}{c|}{} & Japanese & New European \\
\hline $\begin{array}{l}\text { Full power of vehicle } \\
\text { during braking, \% }\end{array}$ & 100 & 100 \\
\hline $\begin{array}{l}\text { Maximal recovered } \\
\text { power, series drive } \\
\text { (including losses for } \\
\text { tire heat), \% }\end{array}$ & 60,14 & 51,93 \\
\hline $\begin{array}{l}\text { Maximal recovered } \\
\text { power, parallel drive } \\
\text { (including losses for tire } \\
\text { heat), \% }\end{array}$ & 30,07 & 34,46 \\
\hline
\end{tabular}

Series drive allows to receive the greatest percent of energy recovery both for Japanese and for new European driving cycles. Thus the best result is obtained for the Japanese driving cycle, which is directly connected with percent of braking time during the cycle $(52,3 \%$ for the Japanese driving cycle against $24,9 \%$ for New European driving cycle).

The parallel drive provides not such high percent of energy recovery, however shows its stability for mentioned driving cycles.

The following variants for increasing of recovered energy during braking are possible:

- application of new drive configurations (an example - the mixed configuration of hybrid vehicle Toyota Prius);

- $\quad$ since during braking the great instantaneous power is generated with its subsequent attenuation it is necessary to develop storage elements that will be capable to save up as much recovered energy as possible during the first $3-5 \mathrm{sec}$ of braking;

- $\quad$ to use new capacities (new types of batteries, ultracapacitors) for storage of recovered energy;
- to increase efficiency of braking due to full use of traction coefficient on the road.

\section{Conclusions}

The carried out review and research have shown two basic approaches to the organization of drive which are applied for hybrid cars. Nowadays there are more and more new configurations of drive for hybrid vehicles which are both derivative of two main principles, and essentially new. The choice of the concrete engineering scheme should be a subject of the careful functional cost analysis, however for the subsequent research it is meaningful to give a number of recommendations:

1. It is reasonable to apply perspective electromechanical brake drives which allow to solve the problem by reducing power takeoff necessary for a drive of brake devices.

2. The increase of recycling degree for recovered energy can be found with application of new schemes and configurations for systems of regenerative braking, and also new capacities for accumulation of recovered energy.

3. Analysis of virtual tests results shows the necessity of taking into account the operation conditions for a vehicle with regenerative brake system.

\section{Acknowledgement}

Author would like to thank IMAGINE S. A. Company for license of AMESim ${ }^{\circledR}$ software granted for Belarusian National Technical University

\section{References}

1. BRAESS, H.-H.; SEIFFERT, U. Vieweg Handbuch Kraftfahrzeugtechnik. Friedrich Vieweg \& Sohn Verlagsgesellschaft mbH, Wiesbaden, 2000.

2. YAMAGUCHI, J. Blue skies at Makuhari. Automotive Engineering International, 2006, No 1, p. 55-62.

3. Fuel cell technology handbook. Edited by G. Hoogers. CRC Press, 2003.

4. http://downloads.openchannelsoftware.org/HEVA

5. http://www.amesim.com

6. Hand book of automobiles (Автомобильный справочник). Moscow: Za ruliom, 2000, 896 p. (in Russian).

7. SANTINI, D.; VYAS, A.; ANDERSON, J.; AN, F. Estimating trade-offs along the path to the PNGV $3 \mathrm{X}$ goal. Transportation Research Board 80th Annual Meeting, Washington, DC, January, 2001. 